\title{
infância, ética e amorosidade na experiência da aprendizagem
}

\author{
lisandra ogg gomes ${ }^{1}$ \\ universidade do estado do rio de janeiro, brasil \\ sammy william lopes ${ }^{2}$ \\ universidade do estado do rio de janeiro, brasil
}

resumo

Apresentamos neste texto reflexões e análises pautadas nos campos filosófico e sociológico a respeito da infância e da educação das crianças, tomada a partir da relação entre os conceitos de ética, estética, afeto e amorosidade. Inicialmente, postulamos que a educação das crianças deve envolver a concepção coletiva de um plano curricular ético e afetivo, apto a acolher e explorar a força vital da infância como componente educativo fundamental. Dessa forma, avaliamos como imprescindível à consecução de tal modo afetivo de aprendizagem, a constituição de uma modalidade diferencial de interações amorosas (seja entre crianças e adultos, entre elas, e delas com o mundo e a vida), capaz de engendrar as singularidades por meio das quais o movimento ético-estético e político de uma educação para a potência da infância possa conceber-se. A partir desses encaminhamentos, nos dedicamos ao desenho dos princípios básicos capazes de sinalizar uma imagem conceitual plausível para uma educação ético-afetiva das crianças. Educação esta, orientada a assumir a brincadeira como plano de experimentação do díspar, aberto ao devir das forças de indeterminação - inerentes às relações sensíveis, imaginativas e intelectuais - que articulam social e culturalmente o ato de aprender e ensinar. Nosso esforço é o de colocar em discussão os imperativos de uma educação pautada em preceitos e práticas que tentam não eliminar ou minimizar, mas estabelecer uma relação positiva, atenta e sensível com as diferenças que a infância e as crianças forçosamente nos impõem.

palavras-chaves: infância-criança; educação; ética; afeto; brincadeira.

\section{childhood, ethics and amorousness in the learning experience}

abstract

In this text, we present reflections and analyses based on the philosophical and sociological fields about the childhood education, taken from the relation among the concepts of ethics, esthetics, affect and amorousness. Initially, we postulate that education of children should involve, necessarily, the collective conception of an ethical and affective curricular plan, able to welcome and to explore the vital force of childhood as a fundamental educational component. Thus, we evaluated as essential to the achieving of this affective learning mode, the constitution of a differential modality of amorous interactions (either between children and adults, whether among themselves, and from them to the world and the life), capable of engendering the singularity through which the ethical-aesthetic and political movement of an education for the childhood's potency can be conceived. From these referrals, we dedicate to the drawing of the basic principles able to sign a possible conceptual image for an ethical-affective children's education. This

\footnotetext{
${ }^{1}$ E-mail: lisandraogg@yahoo.com.br

2 E-mail: samwlopes@gmail.com
} 
education is oriented to take on the children's playing as a pure plan of the uneven experimentation, opened to the come-to-be indetermination's forces - inherent to the sensitive, imaginative and intellectual relations - that articulate social and culturally the act of learning and teaching. Our effort was to put in discussion the imperatives of an education based on precepts and practices that try not to eliminate or minimize, but to establish a positive, attentive and sensitive relationship with the differences that childhood and children forcibly impose on us.

keywords: childhood-children; education; ethics; affection; children's play.

\section{infancia, ética y amorosidad en la experiencia de aprendizaje}

resumen

Presentamos en este texto reflexiones y análisis fundados en los campos filosófico y sociológico con respecto a la infancia y la educación de los niños, considerada a partir de la relación entre los conceptos de ética, estética, afecto y amorosidad. Inicialmente, postulamos que la educación de los niños debe relacionarse con la concepción colectiva de un proyecto curricular ético y afectivo, apto para acoger y explotar la fuerza vital de la infancia como componente educativo fundamental. Así, evaluamos como imprescindible la consecución de dicho modo afectivo del aprendizaje, la constitución de una modalidad diferencial de las interacciones amorosas (sea entre niños y adultos, entre ellos, y de los mismos con el mundo y la vida), capaz de engendrar las singularidades a través de las que el movimiento ético-estético y político de una educación para que la potencia de la infancia pueda concebirse. A partir de dichos caminos, nos dedicamos al diseño de los principios básicos capaces de señalar una imagen conceptual plausible para una educación ético-afectiva de los niños. Educación que está orientada a asumir el juego como plano de experimentación de lo dispar, abierto al devenir de las fuerzas de indeterminación - inherentes a las relaciones sensibles, imaginativas e intelectuales - que articulan social y culturalmente el acto de aprender y enseñar. Nuestro esfuerzo es el de poner en discusión los imperativos de una educación basada en preceptos y prácticas que intentan no sólo eliminar o minimizar, sino establecer una relación positiva, atenta y sensible con las diferencias que la infancia y los niños nos imponen forzosamente.

palabras clave: infancia-niño; educación; ética; afecto; juego infantil. 
infância, ética e amorosidade na experiência da aprendizagem

\section{infância, escola e felicidade ${ }^{3}$}

É comum os pais dizerem aos seus filhos: queremos que você seja feliz. Mas, o que é a felicidade? A sua felicidade e a minha felicidade não serão sempre, e por natureza, realidades mais ou menos distintas? Não estaríamos com isto buscando tornar a felicidade alheia uma espécie de exigência, ou seja, tentando normatizar o que deve ser a felicidade do outro a partir de preceitos particulares?

Certamente que a criança pode, precisa e deseja ser "feliz". Isto se tomarmos a "felicidade" como expressão de uma alegria, como uma experiência intensiva e afetiva (sensível, memorial, imaginativa e intelectual); que gera um sentimento de realização, um sentimento subjetivo de composição com o entorno. Tal alegria ${ }^{4}$ promove, portanto, o aumento da potência de agir-pensar do corpo infantil, a partir de sua experiência interativa com o mundo e com a vida; expressando a possibilidade de participação ativa da criança no jogo sociocultural de coprodução do real, do social e do idealizado.

Deste ponto de vista, a imagem de um modelo único de "felicidade" não poderia nem precisaria ser figurada e imposta pelos adultos (familiares, médicos, psicólogos, educadores, sociólogos, etc.), que cercam e enquadram a infância em espaços-tempos limitados a percepções particularistas e técnico-científicas do que deveria ser o futuro ideal e feliz. Diante dessa questão, ao invés de nos abrirmos a uma aprendizagem acerca dos sentidos diferenciais que a felicidade pode assumir na infância, tentamos impor às crianças expectativas de felicidade que, mais intimamente, são nossas. Expectativas essas, usualmente balizadas em modelos socioeconômicos, cognitivos e culturais dominantes.

Podemos dizer, por conseguinte, que tal processo social de construção de uma noção (mais ou menos comum) de felicidade, se fundamenta em um conjunto

\footnotetext{
${ }^{3}$ Agradecemos o carinho-atenção amorosamente dispensado pela Professora Doutora Vera Maria Ramos de Vasconcellos na leitura e alinhavo das linhas de escrita desse texto.

${ }^{4} \mathrm{E}$ todas as paixões, em seus detalhes, Spinoza vai engendrá-las a partir desses dois afetos fundamentais: a alegria como aumento da potência de agir, a tristeza como diminuição ou destruição da potência de agir. (DELEUZE, 2010, p.13).
} 
de valores, normas, ideias e práticas objetivadas pelos indivíduos e também pelas instituições destinadas à infância. No caso das instituições escolares, esse processo é difundido especialmente no currículo, através da valorização de determinadas ações e discursos, os quais devem estar de acordo com as normas básicas de conservação, as quais são estabelecidas socialmente. Opera-se, de fato, uma tentativa de normatização e individualização do sentido da felicidade pautada em expectativas de ordem econômica, cultural, ideológica e comportamental.

O que se toma por felicidade em geral não se trata, por consequência, de uma noção efetivamente genérica e informal, mas de tipos ideais de felicidade, datados e moldados biograficamente; tipos que tendem a ser reproduzidos pelos indivíduos e grupos sociais; mas que em hipótese alguma devem traduzir-se, necessariamente, em passividade, docilidade ou submissão. São expectativas mais ou menos similares, construídas a partir de abstrações idealizada de um fenômeno, que auxilia a compreender o idealizado e o real (WEBER, 1987; BAUMAN, 2008).

Defende-se, assim, que a tarefa fundamental de um processo educativo, que possa se configurar verdadeiramente emancipatório, permita que as crianças conquistem (por linhas de força ou meios artísticos que lhes são muito próprios) um maior grau da potência de pensar e de agir. Isto, no sentido de afirmá-las como coprodutoras de saberes, valores, atitudes e posturas ético-estéticas, necessárias para desabrocharem no mundo como forças ativas de criação.

Desse modo, o ato de educar se configura como um espaço-tempo dedicado a explorar a efetividade de práticas políticas de participação, ou seja, à "des-hierarquização" das relações de aprendizagem-ensino. Relações por meio das quais procuramos, de forma usual e contrariamente à lógica da participação, impor às crianças noções dominantes e particularistas do mundo e da vida, supostas necessárias para a construção de certa imagem de felicidade, capaz de figurar abstratamente um futuro ideal.

Presume-se, neste sentido, que a instituição escolar, dedicada à educação da infância, pode se constituir tanto como um espaço-tempo mais democrático de 
produção, afirmação e exploração dos modos diferenciais de sociabilidade que as crianças engendram, quanto como um ambiente mais democrático de socialização, isto é, com fóruns, espaços ou locais para a prática ética e política (DAHLBERG; MOSS; PENCE, 2005). Tornando-se, em todo caso, um local de prática política e, especificamente, de prática política-democrática, visto que a educação é muito abrangente e engloba aprendizagem, cuidado e formação, ou seja, “[...] educação em seu sentido mais amplo" (MOSS, 2009, p. 418).

De maneira mais sensível, a referida prática política-democrática se concretiza por meio da efetivação da possibilidade de participação ativa das crianças no diagrama político em que o real-social ${ }^{5}$ se engendra. Possibilidade essa que só pode desenrolar-se a partir da des-hierarquização das relações de aprendizagem e ensinância. Considerando-se que o ato de aprender-ensinar, tomado aqui de forma complexa e politicamente muito implicada, engloba de modo necessário e em seu sentido mais essencial, uma experiência de natureza intensiva e afetiva que ultrapassa o imperativo da recognição ${ }^{6}$. Assim, orienta-se para a necessidade de afirmação da diferença, da multiplicidade, da alegria e da experimentação - isto é, de uma ideia de formação entendida enquanto processo sociocultural de produção de um singular, o qual se expressa na busca pela produção de noções comuns.

[...] Quando as relações que correspondem a dois corpos [quaisquer] se compõem, os dois... formam um conjunto de potência superior, um todo presente nas suas partes... [Assim] a noção comum é... uma composição entre dois ou vários corpos e [mais profundamente a]... unidade dessa composição... ela exprime as relações de conveniência... dos corpos existentes... com efeito, ao [expressar] uma unidade de composição, elas estão tanto na parte como no todo e não podem ser concebidas senão adequadamente... quando encontramos um corpo [qualquer] que convém

\footnotetext{
${ }^{5}$ Seguindo Rolnik (2006, p. 58 a 59), não existe sociedade que não seja feita de investimentos de desejo nesta ou naquela direção, com esta ou aquela estratégia e, reciprocamente, não existem investimentos de desejo que não sejam os próprios movimentos de atualização de certo tipo de prática e discurso, ou seja, atualização de certo tipo de sociedade.... [Portanto] o desejo em seus movimentos corresponde [também] às estratégias de formação de cristalizações existenciais que vêm a ser, exatamente, o desenho de novas configurações no campo social. [De modo que] o desejo [expressa] a própria produção do real social [e vice-versa]... a questão da distinção entre o social e o desejo, entendido como individual ou interindividual, revela-se [então] como falso problema...

${ }^{6}$ A recognição diz respeito à internalização de conceitos preestabelecidos, aplicáveis à prática de reconhecimento do estado e da qualidade de uma coisa ou de um ser, tal e qual enquadrados formalmente no conceito correspondente.
} 
com o nosso, experimentamos logo um afeto ou um sentimento de alegria-paixão, apesar de ainda não conhecermos adequadamente o que tem de comum conosco [tal adequação se efetiva concretamente]. Jamais a tristeza, que nasce do nosso encontro com um corpo que não convém com o nosso, nos induziria a formar uma noção comum; mas a alegriapaixão, como aumento da potência de agir e de compreender, induz-nos a fazê-lo: é a causa ocasional da noção comum. (DELEUZE, 2002, p. 9899).

\section{por uma educação diferencial e a ordem do social na educação da infância}

Nos termos desta educação ética e estética, politicamente orientada à afirmação da alegria como componente educativo essencial; o ato de aprenderensinar se desenrola segundo um processo permanente de desterritorialização e reterritorialização $0^{7}$ dos saberes, valores, atitudes e posturas - produzidos e apresentados pelo grupo de trabalho como úteis e necessários ao tratamento das questões surgidas nos encontros entre o corpo infantil e o mundo. Encontros por meio dos quais as crianças podem experimentar um enlace afetivo de si com outrem, ou seja, com a força do que difere.

Aborda-se aqui, deste modo, uma educação dedicada à instauração e exploração de uma busca constante pela afirmação do corpo infantil como vetor de produção de novos sentidos políticos possíveis para a acepção criadora do verdadeiro.

Nesse contexto, pergunta-se: enquanto professores, como poderíamos intervir em função de que as crianças possam conquistar essa autonomia ética de si no encontro com o mundo? A resposta é aparentemente muito simples; ainda que, absolutamente, não simplista: só podemos proceder a isso amando-as verdadeiramente, mas conforme um modo muito especial de amar, ao mesmo tempo sensível, atencioso, acolhedor e indagador. Não se trata, evidentemente, de amá-las ao estilo de um amor burguês ${ }^{8}$ que, de forma habitual, caracteriza as

\footnotetext{
${ }^{7}$ Cf. Deleuze (1998, p. 155-156).

8 Trata-se daquele amor que deve ser venerado, o amor que não tem motivos, basta ser pronúncia de amor e um deve-me algo já está implícito. "Por amor" e "pelo amor" faço isso ou aquilo e pronto, tu me deves... esses mandos e desmandos de duplo vínculo estão presentes não só na família, mas em todas as nossas relações de modo geral, e cumprem muito bem o papel de solapar com a energia espontânea e criativa da potência de vida, instalando as vigílias sutis e difusas do autoritarismo e da submissão. Disponível em <http://www.eternoretorno.com/sobre-o-amorburgues/>.
} 
práticas educadoras dominantes. Mas de amá-las deixando-se afetar por elas; expressando tal afeto por meio da intensidade contida em um gesto de atenção, de sensibilidade, de escuta e disponibilidade para o exercício conjunto do pensamento.

Tudo isso, em outras palavras, diz respeito a procurarmos convidar as crianças a participarem de um jogo educativo mais aberto e participativo de produção do entendimento; consagrado, especialmente, à busca pela criaçãoenunciação de um novo. Instigando-as a desdobrarem uma continuidade inventiva para as linhas rizomáticas de ação e pensamento ${ }^{9}$ que elas rabiscam e fazem entrelaçar em suas conversas em meio à experimentação da diferença. Inserindo-as na dinâmica de um encontro capaz de valorizar as singularidades em concepção e afirmar as potencialidades para que essas se multipliquem, conforme um movimento comunitário de composição de contornos simultaneamente, comuns, inusitados, inovadores e possíveis.

Por conseguinte, não se trata de uma recomendação pedagógica, de natureza metodológica técnico-científica, preconizada a uma professora desejosa por efetuar uma performance educativa segundo o modelo competente de ensinar. Aborda-se, ao contrário, a possibilidade de tentarmos constituir uma estética e uma ética com a infância; de traçar com ela um modo criativo de mútua-afetação, de mútua potencialização e de mútua aprendizagem, cuidado e formação.

Em função do exposto, poderíamos conceber diferencialmente a noção de "coletivo", tomando-a como relação de composição que se efetua entre diferentes forças (ou diferentes graus intensivos de potência de vida), em função da necessidade de constituição de um comum; o qual só pode expressar-se na forma de uma singularidade emergente, sempre por ser constituída. Igualmente, as instituições que se ocupam da infância, favorecem dinâmicas de produção de encontros entre as crianças (e entre elas e os adultos), configurando-se essencialmente como espaços-tempos de socialização e de produção de sociabilidades.

\footnotetext{
${ }^{9}$ Cf. Deleuze (1995, p. 11-37).
} 
As instituições para a infância são espaços onde as crianças se socializam e sociabilizam, ou seja, são elas que atuam nos seus processos de socialização a partir das normas e valores dados. As crianças participam de incontáveis processos sociais nos quais ao mesmo tempo em que interferem e atuam, têm de lidar com as regras institucionais. Portanto, as crianças vivem uma pluralidade de disposições e de competências, por um lado, e uma variedade de contextos de sua efetivação, por outro (LAHIRE, 2006). O que está posto é que a escola para a infância é um dos universos sociais das e para as crianças, e ainda uma matriz de socialização ${ }^{10}$ fundamental.

Os universos, as instituições e os grupos são múltiplos, mas não se pode esquecer que são as crianças que constroem suas experiências, as quais são atravessadas por essa diversidade que nem sempre é compatível, acumulável e quase sempre é contraditória, visto que as instâncias de socialização têm seus próprios interesses e lógicas. Nessa linha, é possível afirmar que as crianças são atores sociais, pois, como a metáfora da dobradura, cada dobra feita, refeita, amassada, amarrotada revela a multiplicidade e complexidade dos processos e das dimensões das lógicas sociais que elas experienciaram e interiorizaram (LAHIRE, 2002).

Ademais, Cléopâtre Montandon (2005) avalia que nesses espaços institucionais a ordem sensível e afetiva configura-se como uma das expectativas de maior relevância para as crianças, que reconhecem da mesma maneira a importância das regras, das orientações e da confiança.

[...] as crianças de hoje vivem em sociedades as quais permitem, mais que antes, que se discuta livremente, e que derrubaram a autocracia. Se elas parecem menos submetidas e mais críticas é porque estão sintonizadas com a evolução de sua sociedade. Entretanto, ao mesmo tempo, fazem parte do grupo das crianças: vivem, portanto, a relação de poder assimétrica consubstancial à infância - são mais fracas perante os adultos, sem esquecer que, do ponto de vista econômico, são as primeiras a serem afetadas (MONTANDON, 2005, p. 503).

\footnotetext{
10 De acordo com Setton (2009), as matrizes de socialização, como, por exemplo, mídia, escola, família e instituições religiosas, são produtoras de valores culturais e referências identitárias.
} 
Nesse contexto, a afirmação da possibilidade para o devir de uma educação infantil ético-afetiva11 realiza-se, também e necessariamente, a partir do enfrentamento de um campo problemático fundamental: como as professoras podem melhor expressar seu amor pela infância ${ }^{12}$ se, de maneira geral, encontramse enredadas no âmbito de políticas oficiais de formação, currículos e instituições escolares "legalmente" dominadas por forças de maioria, de modo usual, conservadoras e sedentárias? Isto é, como poderíamos escapar aos imperativos seculares que nos induzem a atribuir à educação escolar uma função predominantemente ortopédica?

Ao mesmo tempo, porém de outro ponto de vista, caberia perguntar: mas então, como as professoras conseguem, mesmo que de forma ocasional, acolher e explorar afirmativamente as multiplicidades, singularidades ou modos diferenciais de vida-pensamento que as crianças nos propõem o tempo todo? Como e por que se autorizariam a abrir mão da necessidade de enquadrar a infância em determinadas prescrições cognitivistas e comportamentais, socialmente reconhecidas como 'normais' e 'desejáveis'? Como elas alcançariam a alegria de não ter de punir aqueles que desobedecem, resistindo à retidão da ordem moralista que classifica seus modos diferenciais de ação e pensamento como exceções inconvenientes à regra? Enfim, como arrumam para escapar aos imperativos invisíveis que as constrangem a negar e impedir o devir da potência criadora de compreender e agir das crianças, a favor de conformá-las mais facilmente à imagem de cópias ideais dos padrões de maioria preestabelecidos?

\section{infância e afeto}

Entendemos que uma abordagem possível para começarmos a enfrentar a natureza complexa dos problemas colocados estaria, em grande parte, associada à produção da capacidade de experimentar a noção de infância a partir de um ponto

\footnotetext{
${ }^{11}$ Cf. Merçon (2009, p. 61-80).

${ }^{12}$ A conjunção criança-infância é tomada na filosofia Deleuzeana como um processo co-implicado, no qual a própria experimentação do devir-criança (quando um corpo-hominídeo, em qualquer idade cronológica, entra em uma relação ética e criadora de composição com a força da diferença) caracteriza a infância enquanto puro acontecimento.
} 
de vista de inflexão. Perspectiva esta, capaz de romper com os modelos predominantes os quais, habitualmente, tomam a infância como uma etapa precária da vida. E, a partir daí, atribuem às crianças certa condição natural de carência, que as identifica enquanto seres associais, determinados primordialmente pela necessidade de efetuarem certo processo de desenvolvimento. Processo esse, associado a faltas de caráter psíquico, sensóriomotor, cognitivo, cultural e de outras ordens preestabelecidas, decalcadas sobre o corpo infante conforme o sentido geral do humano. De forma que, assim, as crianças passam a ser compreendidas como seres que pouco têm a contribuir com a sociedade e, facilmente, nem sequer lhes seja permitido participar - embora tal participação aconteça desde seu nascimento.

Nestes termos, quando as professoras ganham força vital, autorizando-se a mover a ordem das linhas de desejo ${ }^{13}$ que determinam seu fazer educativo, elas podem deslocar suas políticas desejantes e intelectuais para pontos desiguais de perspectivas - distintos daqueles que exigem que as crianças se apresentem como imitações perfeitas das cópias ideais socialmente preconcebidas para um corpo infantil normalizado ${ }^{14}$. Em tal contexto, vislumbra-se possibilidades muito concretas para a experimentação de movimentos curriculares verdadeiramente mais amorosos ou menos hierárquicos e autoritários ${ }^{15}$. Movimentos esses orientados, de modo geral, à exploração da possibilidade educativa de se compor relações éticas, estéticas e políticas mais participativas, criadoras e inventivas com a força de diferenciação da infância; conforme o traçado de uma experiência afetiva de aprendizagem dedicada, nomeadamente, à constituição de noções comuns de natureza especial, em outras palavras, de agenciamentos coletivos de enunciação ${ }^{16}$ dedicados à necessidade de concepção de um singular no fluxo constitutivo da ideia no pensamento ${ }^{17}$.

\footnotetext{
${ }^{13}$ Cf. Rolnik (2006, p.49-54).

${ }^{14}$ Cf. Foucault (2009, p.147-171).

${ }^{15}$ Isto não significa que não podemos, em determinadas circunstâncias, convidar a criança a refletir sobre uma necessidade social que lhe inflige certa mudança de comportamento.

${ }^{16}$ Cf. Deleuze; Guattari (1995, p.16-18).

${ }_{17}$ Cf. Deleuze (2005, p.201-213).
} 
Por conta do exposto, faz-se necessário esclarecer a natureza muito específica do que estamos a entender aqui por afeto, a partir mesmo da ideia mais básica e associada de afecção.

Nos nossos termos, o corpo infantil (assim como o corpo adulto) encontrase permanentemente exposto à experimentação dos efeitos provocados sobre ele, em meio aos encontros que traça com outros corpos. Considerando com Deleuze (2002) que um corpo pode ser qualquer coisa, pode ser um animal, um corpo sonoro, uma alma ou uma ideia; pode ser um corpus linguístico, um corpo social [e cultural] ou uma coletividade. De forma que são essas afecções - os efeitos de toda espécie provocados no encontro dos corpos - que designam o que acontece ou as modificações que o corpo infante experimenta no seu enlace com o mundo.

De forma muito concreta, seguindo ainda com Deleuze (2002), as referidas afecções se exercem provocando a formação de imagens ou de marcas sobre os corpos envolvidos no dito encontro, assim como, as ideias que a partir delas o corpo elabora, associam ao mesmo tempo tanto a natureza do corpo afetado quanto a do corpo exterior afetante. Podemos designar como imagens formadas das coisas, as afecções experimentadas pelo corpo, cujas ideias se constituem por meio de uma representação afetiva da natureza dos corpos exteriores.

No entanto, o que há de mais interessante em tudo isso, é que a ordem das afecções-imagens ou ideias então formadas, passam a determinar o estado atual do corpo e do espírito afetado, implicando a experimentação de um maior ou menor grau de perfeição em relação ao estado precedente. Isto é, o corpo experiencia uma variação (para mais ou para menos) em sua capacidade de agir e pensar.

[...] de um estado a outro, de uma imagem ou ideia a outra, há, portanto, transições, passagens vivenciadas, durações mediante as quais passamos para uma perfeição maior ou menor. Ainda mais, esses estados, essas afecções, imagens ou ideias, não são separáveis da duração que as relaciona ao estado precedente e as induzem ao estado seguinte. Essas durações ou variações contínuas de perfeição [posse de potência] são chamadas afetos. (DELEUZE, 2002, p. 55).

Desta maneira, os afetos assumem uma função primordial na possibilidade de concepção de uma educação ética, estética e política para infância, uma vez que tornam indiscerníveis os termos que compõem a relação 
sujeito-objeto ${ }^{18}$ no fluxo da experiência de produção do entendimento. De forma que a busca pela compreensão não poderia mais ser desvinculada da ideia de corpo (ou da perspectiva de sua natureza afetiva). Isto é, do corpo pensado enquanto um conjunto de relações interiores-exteriores, em movimento permanente de configuração e reconfiguração de si, conforme a ordem muito dinâmica dos encontros que rabisca incessantemente com o mundo.

A possibilidade de realizar o referido estilo sensível e afetivo de educar guiar-se-ia, portanto, conforme a necessidade de investigarmos, seja como deslocar o lugar do poder dominante que procura o tempo todo, se sobrepor e conduzir os sentidos da docência, seja como melhor acolher e deixarmos nos envolver mais intensivamente com as multiplicidades exaladas pela infância afetando-se com a força do que nela difere, brincando com a disparidade que se impõe, experimentando e explorando junto com as crianças os novos mundos que elas propõem fazer desabrochar neste mundo ${ }^{19}$.

Neste movimento de experimentar, explorar e pensar junto, fazer com que elas se detenham um pouco mais sobre a dessemelhança experienciada, selecionando no $\operatorname{caos}^{20}$ um e outro ponto fulgurante. Procurando então traçar com eles um plano de relações (um plano geométrico ou de composição) apto a conceber, por meio de um processo coletivo, estilos desiguais ou singulares de entendimento; os quais só podem se constituir no entre espaço-tempo em que a diferença as desterritorializa, forçando-as a buscar, segundo a tentativa de criação de um novo (ou do que ainda não há), um modo de reterritorialização possível.

\section{a infância do futuro no futuro da infância: formalismo educacional e as potências da infância}

Conforme a abordagem em discussão, as propostas instituídas para a educação escolar da infância não teriam mais a necessidade, não mais se restringiriam à função de reproduzir o que se designa hierárquica e

\footnotetext{
${ }^{18} \mathrm{E}$, por consequência, a própria relação teoria-prática.

${ }^{19}$ Cf. Deleuze (2005b, p.207-209).

${ }^{20}$ Cf. Deleuze; Guattari (1992, p.59-61).
} 
autoritariamente como saberes, valores, crenças, atitudes e posturas "prioritárias" - produzidas e acumuladas pelas culturas dominantes (e amplamente reproduzidas nos currículos oficiais); os quais as crianças precisariam internalizar no sentido de que se possa garantir a consecução de sonhos políticos supostamente "comuns" para o futuro feliz de "nossa" sociedade capitalista técnico-científica, sustentada por um perverso regime de exclusão.

É possível argumentar que na atualidade caminha-se cada vez mais para a desinstitucionalização da escola - segundo os termos de Dubet (1998) -, que exige do indivíduo a construção por si mesmo dos sentidos das suas experiências, as quais se constituem entre diferentes variáveis que envolvem a emoção e a razão, o subjetivo e o objetivo.

Parece-nos então inadequado justificar que a educação ajuda a construir uma espécie de futuro genérico e ideal para todos; seja porque, como vimos, não somos necessariamente felizes da mesma maneira, seja porque as crianças, dentre outros atores sociais, não são convidadas para ajudar a traçar uma imagem possível para o referido sonho no decurso do processo educativo. Apenas pesamos-lhes a imposição da responsabilidade de (o mais rapidamente possível) abrirem mão de si mesmas, de suas infâncias, para se capacitarem a realizar um sonho de futuro exclusivamente idealizado por uma visão política adultocêntrica, a elas exterior e inacessível. Considerando que essa responsabilidade pela produção de um futuro idealizado não pode ser atribuída às crianças, pois o futuro enquanto uma responsabilidade pertence a todas as pessoas que compartilham de um compromisso político-ético-estético social.

Retiremos, então, da infância o peso dessa absurda obrigação, uma vez que todos que habitam o espaço-tempo presente precisam assumir o encargo de transformar os modos aéticos ou não amorosos de relação que temos traçado com o entorno, com nós mesmos e com todas as formas de vida.

Mas, é certo que o futuro se estende por uma área muito ampla e múltipla, de forma que seu planejamento deve ser muito mais cuidadoso. $O$ futuro pertence ao domínio da prudência - necessitamos e devemos ter a capacidade de prever os 
eventos que ocorrerão - e está subordinado ao domínio da providência precisamos ter habilidade para nos prepararmos para as necessidades que virão (CASSIRER, 1994).

Ainda que a dita figuração do futuro seja oferecida às crianças, pois considera-se que ele será vivido por essa geração, é preciso ter claro que, embora ainda esteja por vir, o futuro já existe potencialmente. Isso significa compreender que qualquer ação ou transformação contemporânea não afetará apenas as futuras gerações, mas as ordens geracionais como um todo, uma vez que as relações sociais que traçamos com o mundo estão sempre concatenadas e sensivelmente imbricadas entre si. Ainda vale ressaltar que a ideia de que o futuro pertence à infância é uma construção social, estabelecida a partir de disposições e configurações articuladas entre os indícios do passado, as atuações no presente e as conjecturas futuras.

Faz-se necessário aprofundarmo-nos um pouco mais acerca das possibilidades concretas de, enquanto educadores, deixarmo-nos envolver mais produtivamente pelos traços éticos e estéticos informes, rabiscados pela força da diferença no acontecimento da infância. Ou seja, por uma experimentação imprescindível à produção de uma relação afetivo-amorosa de aprendizagemensinância; especialmente orientada ao engendramento de imagens mais abertas e participativas do futuro; tingidas com, a partir da, e em meio à própria natureza múltipla e singular do corpo infante.

Sendo assim, no contexto da tradição formalista da escolarização da infância, a educação tende a se afirmar como uma verdadeira tábua de salvação para a consecução de um futuro genérico e feliz para humanidade: cientificamente avalizada e socialmente assentida, tal tradição teria o poder de garantir o traçado do referido futuro, conforme uma aplicação rígida, competente e fiel de certa predisposição inquestionável de conteúdos e normas.

Vale destacar ainda que embora, na atualidade, as propostas oficiais para a educação escolarizada das crianças tenham assumido como essenciais as posições políticas de intensão mais protecionista e participativa (o cuidar e educar, 
a criança como sujeito de direito), e mesmo mais abertas à condição ativa da infância (a criança como ator histórico-cultural); tais posições, normalmente, não deixam de salvaguardar o intuito de atribuir ao fazer educativo a responsabilidade de preparar as crianças para serem os artífices adultos de um sonho de continuidade para determinados modelos e padrões socioculturais de maioria. Considerando-se que

[...] GD: a maioria é algo que supõe a existência de um padrão - até quando se vota, [a maioria] não se trata apenas da maior quantidade que vota em favor de determinada coisa. No Ocidente, o padrão de qualquer maioria é: homem, adulto, macho, cidadão [branco e jovem]... O padrão é esse. Portanto, irá obter a maioria aquele que, em determinado momento, realizar este padrão... a imagem sensata do homem adulto, macho, cidadão [branco, jovem]. Mas posso dizer que a maioria nunca é ninguém. É um padrão vazio. Só que muitas pessoas se reconhecem neste padrão vazio. Mas, em si, o padrão é vazio...ao lado disso, o que há? Há todos os devires que são minoria. As mulheres não adquiriram o ser mulher por natureza. Elas têm um devir-mulher...as crianças também têm um devir criança. Não são crianças por natureza. Todos os devires são minoritários. CP: Só os homens não têm devir-homem. GD: Não, pois é um padrão majoritário. É vazio. O homem macho, adulto não tem devir. [O homem] pode devir mulher e vira minoria...eu afirmo: a maioria é ninguém e a minoria é todo mundo... e que é aí que acontece o fenômeno do devir... (DELEUZE, 2009, p. 37).

Deste modo, a diferença essencial que o devir-minoritário da criança engendra e expressa necessariamente, tende a ser desconsiderada como força ativa na propulsão do processo de aprendizagem-ensino; ainda que tal diferença se efetue como componente constituinte fundamental das relações de coprodução que o corpo infantil concebe o tempo todo entre si e o mundo. Nestes termos, a diferença causada tende a ser reduzida a algo associado à natureza pessoal e/ou grupal do indivíduo. Isto é, a algo a ser suportado ou respeitado conforme um índice mínimo de aceitação, ao qual o outro culturalmente inferior, folclórico, abstrato e - fora disso, socialmente invisível; teria direito legalmente.

Entretanto, se quisermos e pudermos nos autorizar à alegria de acolher e afirmar ética, estética e politicamente a infância no contexto de uma escolarização menor, tomando-a enquanto uma potência infinita de diferenciação - dedicada, de modo essencial, à atividade incessante de criação e expressão de singularidades ou de novos possíveis; seria preciso assumir positivamente que, para além da prolixidade de teorias gnosiológicas e curriculares existentes, a infância não deixa 
de, incessantemente, fazer tais aportes saltarem para fora dos seus gonzos, e de projetar possibilidades múltiplas por meio das quais o ato de aprender e ensinar pode se expressar muito distintamente.

Assim, a natureza caótica e muito concreta das indeterminações e imprevisibilidades que o corpo-mente infantil, de forma necessária, experimenta e faz transbordar em meio à ação de educar; inflige um problema significativo à intenção de eleger uma teoria da aprendizagem e um desenho curricular únicos, os quais possam conformar a multiplicidade que jorra, imputando-lhe uma redução técnico-científica.

Para tentarmos ultrapassar os obstáculos e as dificuldades expressas por tais questões, seria preciso ter em mente que a noção de infância não pode ser reduzida aos limites de um fato cronológico ou apenas à condição de uma fase da vida, mas sim a uma categorização construída e reorganizada pelo conjunto da sociedade. Categorização constituída a partir de emoções, experiências, necessidades, desejos e parâmetros socioeconômicos e culturais pré-estabelecidos.

Trata-se, portanto, de compreender que o nascimento de uma criança é um acontecimento singular. Quer se queira ou não as crianças instauram para si e para o mundo uma infância, uma vez que para elas isso significa constituir um modo particular de apropriar-se da cultura, da história e da linguagem, afetando aqueles que a cercam. Na infância tal apropriação só pode ocorrer produzindo fraturas, conflitos, questionamentos, e a possibilidade de concepções de outros estilos de interpretação, de visão e de compreensão do mundo e da vida.

É preciso considerar que a instituição escolar, em geral, não se orienta conforme a possibilidade de lidar com essa variedade de estilos de atuação, interpretação e aprendizagem que as crianças tecem com seu meio social, com o conhecimento já instituído, com a história e a cultura da qual ela é parte. Assim, usualmente a escola acaba por tomar como base para suas intervenções um modelo de infância e criança que é ahistórico, monótono e abstrato (BECCHI, 1979). 
Deste modo, as distintas relações teórico-práticas que comumente tentam determinar a natureza e a ordem das ligações educativas a serem estabelecidos entre o currículo e a infância; tendem a se configurar, elas mesmas, como determinações político-epistemológicas engendradas segundo necessidades e interesses socioculturais, sempre muito específicos e historicamente datados; não podendo, portanto, serem entendidas como construções intelectuais de caráter meramente "técnico-científico". Ao contrário, tais relações teórico-práticas, justo ao se exercerem metodologicamente, assumem um enorme poder de influência sobre o fluxo dos processos de subjetivação em constituição, ou, em outras palavras, na tessitura dos modos de produção de sentido que as crianças precisam conceber para articular um enlace desejante-intelectual de si com o mundo, a partir da experienciação de circunstâncias existenciais diversas.

Evidencia-se, assim, tanto que o ato de educar-aprender nunca poderá ser entendido como uma tarefa meramente "técnico-científica"; quanto, por consequência, que é insuficiente tomarmos o currículo segundo uma imagem linear, sequencial e evolutiva do processo educativo; uma vez que, em função do visto, tal imagem também não garantirá, necessariamente, a consecução exata dos resultados sócio-políticos e culturais esperados conforme a linearidade dos objetivos previstos.

Desta maneira, apesar de ser improvável que o campo da educação em geral se dedique a desvencilhar-se de sua natureza instrutora - no sentido de, inclusive, romper com certa condição de conforto e status que as núpcias seculares com a ciência cartesiana lhe concedem no cenário social. E, adicionalmente, a despeito da já referida prolixidez ${ }^{21}$ atual das teorias-práticas gnosiológicas e curriculares fundadas. Haveria muito a pensar sobre o problema da aprendizagem e da ensinância, caso nos autorizássemos a experimentar a alegria de assumir, afirmativamente, que jamais poderemos saber, de antemão e exatamente, como “a" criança aprende; até porque "a" criança, enquanto um ser padronizado por certa intenção política generalista e conservadora, é uma abstração intratável.

\footnotetext{
${ }^{21}$ José Oiticica, Manual de Estilo (1940, p. 10).
} 


\section{infância no currículo brincante}

As análises que desdobramos até aqui, no entorno das relações de coprodução que se tecem entre as crianças, o mundo e as instituições, evidenciam a possibilidade de se tecer estilos outros de enlace educativo - essencialmente mais sensíveis, memoriais, imaginativos e intelectuais; a serem articulados entre a infância e o movimento do ato de aprender-ensinar, destacadamente, em meio ao que se expressa no currículo como processo de constituição das linhas de afetos ${ }^{22}$ traçadas, especialmente, no fluxo do artifício da brincadeira.

Sabe-se, apesar do que foi discorrido sobre as forças sedentárias predominantes na educação formal, que também não deixam de desabrochar educadores desejosos em fazerem-se mais atentamente sensíveis às múltiplas potências da infância. Entendedores de que tais potências são essenciais à produção de um processo educativo verdadeiramente amoroso; uma vez que expressam o movimento ético, estético e político por meio do qual as crianças procuram desenhar para si um estilo próprio ou um modo singular de enunciação do real; rabiscando, aqui e ali, os traços tortos da diferença que as animam a empreenderem a busca pela concepção de uma singularidade essencial: ontológica, desejante, intelectual, cultural e socialmente necessária.

Assim, são justamente aqueles fios deixados soltos pelas crianças, em meio às experimentações tecidas no do artifício da brincadeira - associada então à possibilidade de exploração educativo-amorosa das imprevisibilidades ou da força do que difere (imanente aos encontros que as crianças traçam com o mundo-vida); que caracterizam a ludicidade como insídia primordial, por meio da qual o corpo infante procura traçar no $\operatorname{caos}^{23}$ um plano afetivo de aprendizagem; orientado à afirmação da necessidade de se conceber um novo ou aquilo que ainda não há.

Considera-se, assim, que diante das circunstâncias comunitárias e alegres de experienciação da indeterminação de sentido - configuradas no encontro das crianças com a disparidade emergente no corpo de outrem; as potências de criação da infância tendem não necessariamente a negar ou desconsiderar tal disparidade;

\footnotetext{
${ }^{22}$ Cf. Rolnik (2006. p.49-54).

${ }^{23}$ Cf. Orlandi (2009, p.145-154).
} 
mas, ao contrário, procurarem acolher e encadear essas linhas de indeterminação de um modo artístico-brincante, virtualmente, muito especial. Dedicando-se então à busca por compor a imagem inventiva de um singular capaz de fazer o pensamento ultrapassar (ainda que de modo muito parcial, precário e provisório) o vácuo de significação e suas evanescências.

De tal ponto de inflexão, é o processo brincante de produção das referidas singularidades brutas, em rascunho no fluxo da experiência infantil de encontroespanto com o mundo; um processo aprendente mais livre, participativo e, sobretudo, fundado necessariamente na celebração da alegria; que pode se configurar como plano de constituição para o esboço de intervenções educativas verdadeiramente mais amorosas. Desde que tais intervenções se orientem a convidar as crianças a buscarem se deter, explorar e expressar (de maneira cada vez mais adequada) a força positiva das diferenciações experienciadas. Isso, no contexto da instauração de uma atividade comunitária, criadora e ética de pensamento; apta, do mesmo modo, a avaliar a importância ou relevância social e individual das novidades então emergentes ${ }^{24}$.

Deixando-se envolver por, e desdobrando-se a partir da instauração do citado plano ético e genético de constituição, as diversas modalidades de relação teoria-prática existentes (e mesmo aquelas por se constituírem) - conforme as ferramentas conceituais que possuem e disponibilizam ao jogo de intercessão poderiam ser mais ativa e dinamicamente complicadas em um esforço coletivo para fazer o ato de educar melhor conformar-se ao fluxo do movimento de diferenciação: tomando-se as relações possíveis de serem estabelecidas entre tais ferramentas, não como verdades absolutas, mas enquanto possibilidades para conceber ações educativas guiadas por arranjos únicos (imbricáveis, configuráveis e reconfiguráveis); imprescindíveis para concebermos, em cada caso, um estilo artístico, ético e estético de acolher e explorar afirmativamente certa porção do caos, imanente à ação de aprender e ensinar.

\footnotetext{
${ }^{24}$ Ou seja, daquela região do espaço-tempo onde as leis da física atualmente conhecidas entram em colapso e as equações perdem o seu significado. (DICIONÁRIO AURÉLIO DIGITAL, 2004).
} 
Percebe-se, desse jeito, que o esboço de tal modo diferencial (caótico, desejante, pensante) de educar com a infância, extrapolaria a dimensão da formação do sujeito da recognição; e dessa forma estaria enredado, também e sobremaneira, às relações que se passam entre infância, produção cultural e atividade lúdica.

\section{infância, cultura e ludicidade}

O movimento da cultura se constitui tanto afirmando territórios subjetivos socialmente constituídos e reificados, quanto afirmando a necessidade de deslocar outros (desterritorialização), modificando-os substancialmente (reterritorialização). Tais movimentos coletivos de produção de cultura, são imprescindíveis à elaboração de novas sensibilidades, novas possibilidades de pensar e agir, bem como de conceber outras normas e códigos que possam dar língua a afetos comuns, os quais expressam “[...] o desmanchamento de certos mundos - sua perda de sentido - e a formação de outros: mundos que se criam para expressar afetos contemporâneos, em relação aos quais os universos vigentes tornaram-se obsoletos". (ROLNIK, 2006, p. 23).

Afetos e linguagens esses, que tendem a ser compartilhados e que podem até mesmo serem rejeitados, mas que de certa forma, engendram uma imagem possível para a experiência vivente atual, desenrolada por certa grupalidade; fazendo com que cada indivíduo se sinta, mais ou menos, parte da referida imagem, comunitariamente atribuída a tal experiência.

Sob este ponto de vista, a cultura "fornece" normas, ideias, códigos e modos de ação os quais, de certa forma, unificam um grupo, fazendo com que cada pessoa se sinta parte de uma mesma totalidade. Nesse sentido, a cultura não é um código que se escolhe simplesmente, mas é algo que está dentro e fora de cada um, como as regras de um jogo sempre em processo, inacabado, simultaneamente subjetivo e objetivo (DaMATTA, 1986).

A cultura lúdica é utilizada pelas crianças para compreender e jogar com um conjunto de regras e significações que perpassam a sociedade da qual participam; constituindo-se a partir das “[...] significações próprias do jogo que o 
jogador adquire e domina no contexto de seu jogo" (BROUGÈRE, 1998, p. 107). É uma cultura produzida pelas pessoas e acionada pela própria atividade lúdica, que exige "[...] a existência do social, de significações a partilhar, de possibilidades de interpretação, portanto, de cultura, para haver jogo" (BROUGÈRE, 1998, p. 113).

O lúdico é parte da cultura de uma sociedade, pois como o homem não consegue se confrontar diretamente com a sua realidade, ele se utiliza de artifícios de intermediação, buscando conhecer pela interposição de formas linguísticas, artísticas e simbólicas para lidar com tal realidade e dar sentido a ela (CASSIRER, 1994). Assim, a atividade lúdica, que envolve o brincar e o jogar, tem uma função significante que encerra determinado sentido, transcendendo as necessidades imediatas da vida (HUIZINGA, 2007). Jogar e brincar são atividades lúdicas fundamentais para todos os indivíduos, e de qualquer idade. Toda e qualquer atividade lúdica é "[...] atividade com orientação própria. [...]. É-lhe reservado, quer material ou idealmente, um espaço fechado, isolado do ambiente quotidiano, e é dentro desse espaço que o jogo se processa e que suas regras têm validade" (HUIZINGA, 2007, p. 11 e 23).

O que queremos pontuar é que a cultura lúdica e as atividades lúdicas são elementos imprescindíveis para que as crianças e os adultos compreendam e apreendam seus espaços e tempos. De toda maneira, é algo que deve ser aprendido, visto que não é inato, mas é uma experiência singular, ao mesmo tempo, adquirida, acumulada, gerada e enriquecida pelas pessoas; através da participação, manipulação e observação de objetos, fatos, contextos e palavras. A cultura lúdica é produto das interações sociais e dotada de significação social, sendo que as crianças e adultos são coprodutores, uma vez que todos são atuantes, interpretes e difusores das significações.

O brincar e o jogar revelam a dimensão criadora humana que abarca a cultura lúdica, uma vez que as crianças são

[...] especialmente inclinadas a buscarem todo o local de trabalho onde a atuação sobre as coisas se dê de maneira visível. Elas sentem-se irresistivelmente atraídas pelos destroços que surgem da construção, do trabalho no jardim ou em casa, da atividade do alfaiate ou do marceneiro. 
Nesses restos que sobram elas reconhecem o rosto que o mundo das coisas volta exatamente para elas, e só para elas. Nesses restos elas estão menos empenhadas em imitar as obras dos adultos do que estão em estabelecer entre os mais diferentes materiais, através daquilo que criam em suas brincadeiras, uma nova e incoerente relação. Com isso as crianças formam seu próprio mundo das coisas, num mundo pequeno inserido em um maior. Dever-se-ia ter sempre em mente as normas desse pequeno mundo quando se deseja premeditadamente para as crianças e não se prefere deixar que a própria atividade - com todos os requisitos e instrumentos - encontre por si mesma o caminho até elas (BENJAMIN, 2002, p. 57).

\section{o devir-amoroso da ação educadora}

É nesse lidar - ética, estética e afetivamente - com o mundo das coisas, que as aprendizagens se conformam e conduzem a certo desenvolvimento; a partir dos processos socializadores e das sociabilidades emergentes vivenciadas e tecidas pelas crianças na experiência coletiva-comunitária de concepção de um comum singular. Experiência essa, que só pode se conformar em meio a um encontro alegre de si com o corpo de outrem.

Caso ainda seja forçoso perguntar: como as professoras podem desencadear e explorar uma busca pela compreensão do que, no referido encontro, atravessa afetivamente o corpo infantil? Sob seu aspecto negativo (ou seja, daquilo que não pode ser), tal questionamento nos obrigaria, antes de tudo e qualquer coisa, a não retomar a ideia de que as crianças são seres frágeis, incapazes e dependentes dos adultos para dirigir a suas atividades e pensamentos; mas

Ao contrário, a criança que surge da observação e da teoria que a vê como um ser histórico-cultural é, desde muito pequena, capaz de explorar os espaços e os objetos que encontra ao seu redor, de estabelecer relações com as pessoas, de elaborar explicações sobre os fatos e fenômenos que vivencia (MELLO, 2007, p. 90).

A partir dessas considerações muito concretas, as quais tentam constituir as condições de possibilidade para se empreender um processo de aprendizagem verdadeiramente amoroso; a educação escolar complicaria (imanente a si mesma) os componentes afetivos, éticos, estéticos e políticos essenciais para desenrolarmos agitamentos curriculares outros. Isso, se aceitarmos que as crianças engendram seu próprio tempo e espaço, conforme um processo singular e co-implicado de 
individuação ${ }^{25}$ e de produção sociocultural. Processo no qual as atividades lúdicas, as sociabilidades e as socializações - assim como os movimentos dinâmicoscinéticos ${ }^{26}$ do enlace desejo-pensamento, articuladores do artifício de subjetivação; se impõem como forças motrizes para que as crianças possam experimentar intensivamente o artifício da aprendizagem, ao mesmo tempo, como causa e efeito de um puro afeto de alegria ${ }^{27}$.

\section{referências}

BECCHI, E. (a cura di). Il bambino sociale Privatizzazione e deprivatizzazione dell'infanzia. Milano: Feltrinelli Editore, 1979.

BENJAMIN, W. Reflexões: a criança, o brinquedo, a educação. SP: Duas Cidades; Editora 34, 2002.

BROUGÈRE, G. A criança e a cultura lúdica. Revista da Faculdade de Educação, São Paulo, vol. 24, no. 02, p. 103-116, jul./dez., 1998.

BAUMAN, Z. Vida para consumo: a transformação das pessoas em mercadorias. Rio de Janeiro: Jorge Zahar Ed., 2008.

CASSIRER, E. Ensaios sobre o homem: introdução a uma filosofia da cultura humana. São Paulo: Martins Fontes, 1994.

DAHBERG, G.; MOSS, P.; PENCE, A. Qualidade na educação da primeira infância: perspectivas pós-modernas. Porto Alegre: ARTMED, 2003.

DaMATTA, R. Explorações: ensaios de sociologia interpretativa. RJ: Rocco, 1986. DELEUZE, G. Cours Spinoza. Disponível em: <http://www.webdeleuze.com/php/sommaire.html>. Acesso em: 21 de set. 2010.

\footnotetext{
${ }^{25}$ Caminhando com Simondom (1989), é por meio do processo de individuação que o corpo infante pode ganhar uma existência enquanto indivíduo; exprimindo-se como tal no fluxo em que o dito processo se desenrola necessariamente. Nestes termos, o indivíduo é apreendido como uma realidade relativa ou como determinada fase do ser que supõe uma realidade pré-individual, anterior a ela, mas que não existe distintamente (mesmo depois do processo de individuação circunscrever-se de forma relativa), pois a individuação não esgota de uma única vez os potenciais da realidade pré-individual. Por outro lado, o que a individuação traz à tona não é só o indivíduo, mas o par indivíduo-meio. Desta maneira, o indivíduo é relativo em dois sentidos: porque ele não é todo o ser, e porque ele resulta de um estado do ser em que ele mesmo não existia, nem como indivíduo nem como princípio pleno de individuação. Assim, a individuação é considerada como resolução parcial e relativa, que se manifesta como um sistema muito complexo, envolvendo múltiplas forças potenciais e encerrando certas incompatibilidades em relação a si mesmo: seja por conta da interação entre forças de tensão, seja em função da impossibilidade de tal interação, no caso de termos extremos pertencentes a dimensões diferenciais que integram o referido sistema.

${ }^{26}$ Seguindo Rolnik (2006, p.39-48), a dimensão dinâmica e cinética do processo desejante diz respeito ao movimento e ao estado de repouso que os corpos podem assumir nos encontros, relacionando tal movimento/repouso, respectivamente, às forças que os induzem e à velocidade das reações físico-químicas que se efetuam entre tais corpos, conforme os fatores afetivos que os ordenam no encontro.

${ }^{27}$ Espinosa, 1980, Proposição XXI, Demonstração, p 140.
} 
. Diferença e Repetição. Rio de Janeiro, RJ: Graal, 2006.

Foucault. São Paulo, SP: Brasiliense, 2005a.

Cinema 2 A Imagem-Tempo. Rio de Janeiro, RJ: Brasiliense, $2005 \mathrm{~b}$.

Espinosa Filosofia Prática. São Paulo: Escuta, 2002.

Diálogos. São Paulo: Escuta, 1998.

; PARNET, C. O Abecedário de Gilles Deleuze. Disponível em:

http:/ / www.oestrangeiro.net/index.php?option=com_content\&task=view\&id=67 \&Itemid=51>. Acesso em: 10 jan. 2009.

; GUATTARI, F. O que é a filosofia. São Paulo: Ed. 34, 1992.

; GUATTARI, F. Mil platôs I. São Paulo: Ed. 34, 1995.

DUBET, F. A formação dos indivíduos: a desinstitucionalização. Revista

Contemporaneidade e Educação, ano 3, vol.3, 1998, p. 27-33.

ESPINOSA, B. de. Ética. Lisboa, Portugal: Relógio D’ Água, 2006.

ETERNO RETORNO. Sobre o amor burguês. Disponível em <

http:/ / www.eternoretorno.com/sobre-o-amor-burgues/ > Acesso em: 11 de ago.

2016.

FERREIRA, A. B. de H. Novo Dicionário Aurélio de Língua Portuguesa. Curitiba:

Positivo, 2004.

FOUCAULT, M. História Da Sexualidade. A Vontade de Saber. São Paulo: Graal, 1988.

LAHIRE, B. A cultura dos indivíduos. Porto Alegre: Artmed, 2006.

MELLO, S. A. Infância e humanização: algumas considerações na perspectiva histórico-cultural. Perspectiva. Florianópolis, vol. 25, nº. 01, jan./jun., 2007, p. 83104.

MERÇON, J. Aprendizado Ético - Afetivo: Uma Leitura Spinozana Da Educação. Campinas: Alínea, 2009.

MOSS, P. Introduzindo a política na creche: a educação infantil como prática democrática. Psicologia USP. São Paulo, vol. 27, no. 3, jul./set., 2009, p. 417-436. OITICICA, J. Manual de Estilo. Rio de Janeiro: Editora Paulo de Azevedo, 1940. ORLANDI, L. B. L. Deleuze: Caos E Pensamento. In: AMORIM, A. C. R; GALLO, S. OLIVEIRA JUNIOR, W. M. de. Conexões: Deleuze e Imagem e Pensamento e... . Petrópolis, RJ: DP et Alii; 2011.

ROLNIK, S. Cartografia Sentimental Transformações Contemporâneas do Desejo. Porto Alegre: Sulina, 2006.

SETTON, M. G. J. A socialização como fato social total: notas introdutórias sobre a teoria do habitus. In: Revista Brasileira de Educação. Rio de Janeiro, vol. 14, nº 41, maio/ago., 2009.

SIMONDON, G. L'individuation psychique et collective: a la lumière des notions de Forme, Information, Potentiel et Métaestabilité. Paris, França: Éditions Aubier, 1989.

WEBER, M. Conceitos básicos de sociologia. São Paulo: Editora Moraes, 1987.

Recebido em: 15.10 .2016

Aceito em: 01.11.2016 